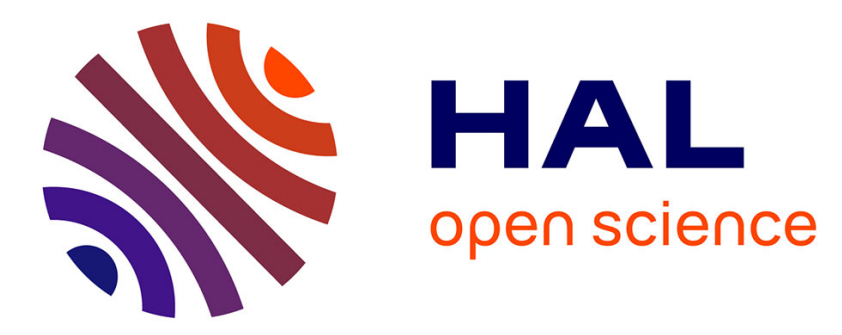

\title{
Elastic behavior of anisotropic terra cotta ceramics determined by kinematic full-field measurements
}

Vincent Huon, Bertrand Wattrisse, Moulay Saïd El Youssoufi, Andre Chrysochoos

\section{- To cite this version:}

Vincent Huon, Bertrand Wattrisse, Moulay Saïd El Youssoufi, Andre Chrysochoos. Elastic behavior of anisotropic terra cotta ceramics determined by kinematic full-field measurements. Journal of the European Ceramic Society, 2007, 27 (5), pp.2303-2310. 10.1016/j.jeurceramsoc.2006.08.013 . hal00572427

\section{HAL Id: hal-00572427 https://hal.science/hal-00572427}

Submitted on 23 Sep 2021

HAL is a multi-disciplinary open access archive for the deposit and dissemination of scientific research documents, whether they are published or not. The documents may come from teaching and research institutions in France or abroad, or from public or private research centers.
L'archive ouverte pluridisciplinaire HAL, est destinée au dépôt et à la diffusion de documents scientifiques de niveau recherche, publiés ou non, émanant des établissements d'enseignement et de recherche français ou étrangers, des laboratoires publics ou privés. 


\title{
Elastic behavior of anisotropic terra cotta ceramics determined by kinematic full-field measurements
}

\author{
V. Huon*, B. Wattrisse, M.S. El Youssoufi, A. Chrysochoos \\ Laboratoire de Mécanique et Génie Civil, Cc 048, Université Montpellier II, Place Eugène Bataillon, 34095 Montpellier Cedex 05, France
}

\begin{abstract}
The anisotropic behavior of terra cotta ceramics is due to the lamellate structure of clay and to the extrusion forming process. In the case of low strains, this behavior is elastic. Digital image correlation was used to give strain field measurements. These measurements allowed to locally characterize transverse isotropic elastic behavior. The consistency of the local characterization procedure is showed by comparing kinematic field measurements on small specimens with fields obtained by 3D finite element computations.
\end{abstract}

(C) 2006 Elsevier Ltd. All rights reserved.

Keywords: Extrusion; Mechanical properties; Traditional ceramics; Structural applications; Terra cotta

\section{Introduction}

Terra cotta ceramics are often used in residential house building. They are nearly always associated with other civil engineering materials, e.g. terra cotta beams with a core of prestressed concrete are widely used for building floors, terraces or flat roofs. In this kind of composite element, terra cotta serves as a sacrifice formwork, i.e. concrete is considered to be the only material that supports prestressing forces. However, from a mechanical standpoint, terra cotta has remarkable strengths (i.e. often better than those of standard concrete) that are often not effectively utilised. The work presented in this paper is a part of an overall study carried out to characterize the anisotropic thermo-hygromechanical behavior of terra cottas used as building material in civil engineering projects. From an industrial standpoint, the goal is to develop numerical computer-aided design tools that can be used to optimize structural elements. This optimization must simultaneously take into account parameters related to thermal comfort and those associated with the mechanical strength of the designed structure.

In the recent past, the classical use of terra cotta bricks did not require in-depth knowledge on their mechanical properties since they were mainly loaded in compression. Now the use

\footnotetext{
* Corresponding author. Tel.: +33467 144737 ; fax: +33 467144792

E-mail address: huon@1mgc.univ-montp2.fr (V. Huon).
}

of the terra cotta as a composite structural component calls for a more rigorous analysis of its contribution to the overall behavior of the structure. We thus studied the heterogeneous and anisotropic properties of this material using strain field measurements. These measurements were obtained by digital image correlation (DIC) techniques with the aim of checking the degree of heterogeneity of ceramic structures and characterizing the anisotropy of the terra cotta. This technique is now widely used in the field of mechanics of materials and it was, for example, successfully applied to the study of localization phenomena in steel (Luders band propagation, developpement of the diffuse and localised necking). ${ }^{1}$

This paper is structured as follows: first we review the material properties that led us to propose a transverse isotropy model to describe the elasticity of ceramics. Secondly, we show how the elastic parameters were locally derived from tests conducted on elementary structures considered as representative volumes of the material. Finally, to check the influence of the discrepancy noted in the elasticity constants, we compare strain patterns predicted by a 3D FE computation with those obtained by DIC.

\section{Material of study: the terra cotta ceramics}

The studied material was provided by the industrial partner "Saverdun Terre Cuite". This manufacturer owns several quarries in the south of France. The used samples were derived from the same raw material. 


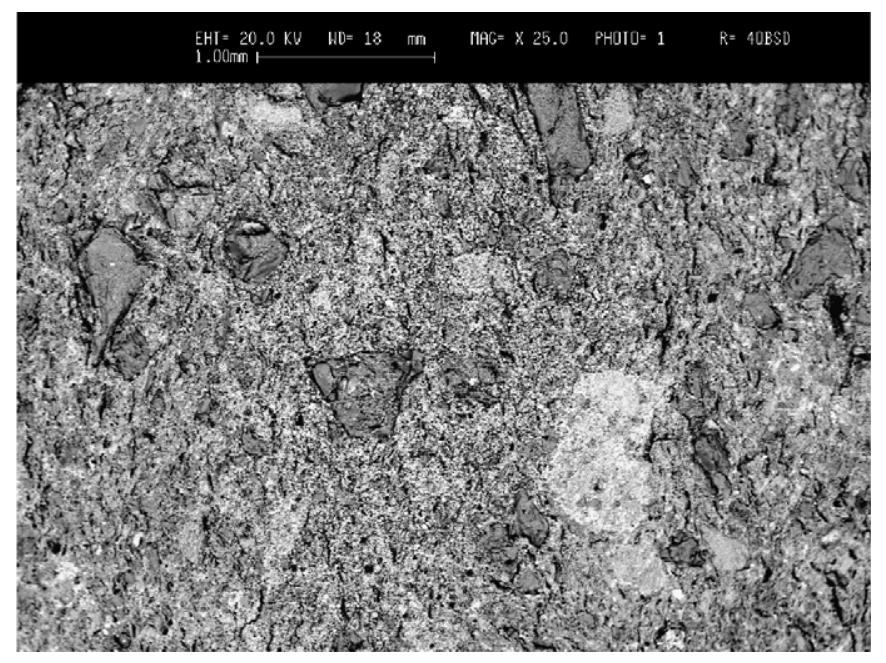

Fig. 1. Illustration of grain size distribution in the material

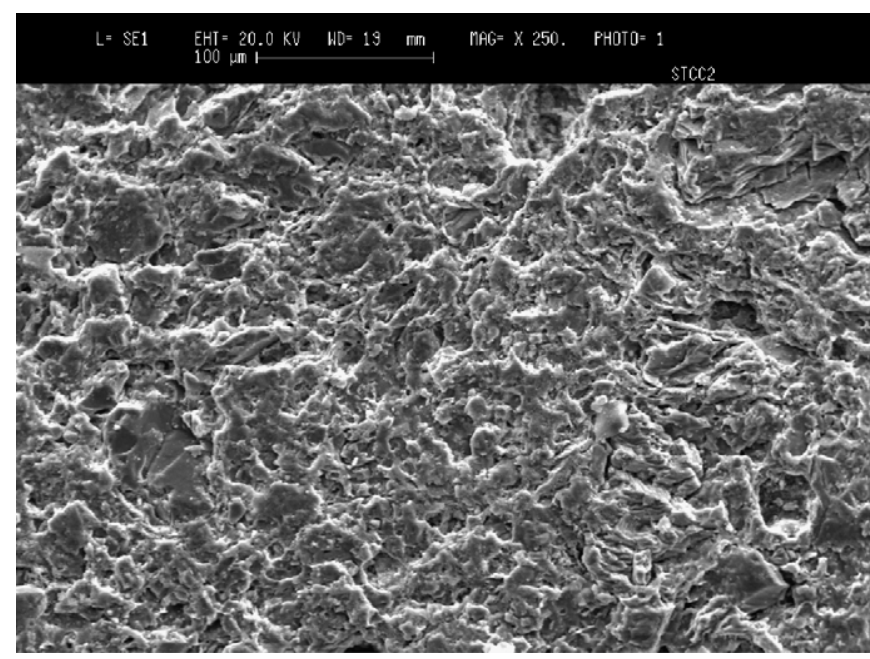

Fig. 2. Illustration of the porosity of the material.

\subsection{Chemical composition}

An electron probe microanalysis (EPM) was used to determine the grain size and nature. The maximum grain size was $1 \mathrm{~mm}$ (Fig. 1), including:

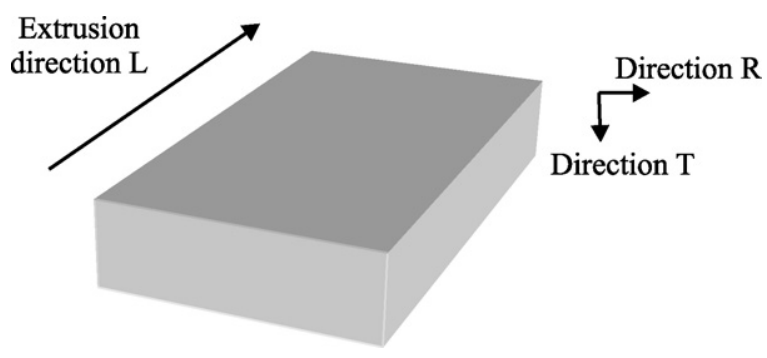

Fig. 4. Directions of transverse isotropy.

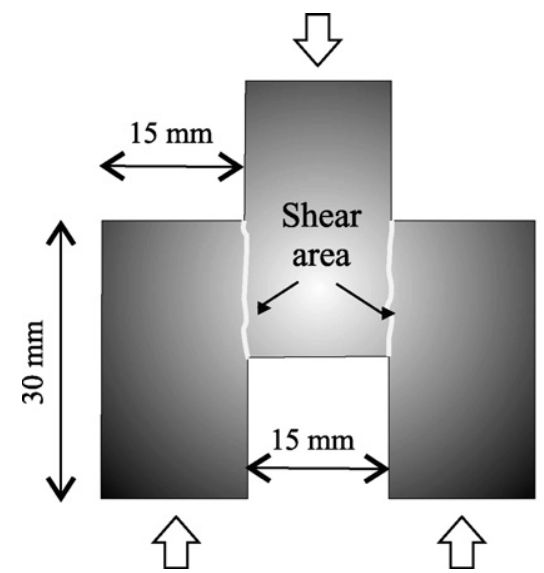

Fig. 5. Y-shaped specimen.

- quartz grains (the most common);

- calcite grains of up to $200 \mu \mathrm{m}$ in size (the least common);

- a low percentage of small feldspath grains.

The chemical composition of the terra cotta studied in this paper is given in Table 1 .

\subsection{Manufacturing process}

Argillaceous soils are the primary products for manufacturing terra cotta ceramics. In most cases, they are used with additives (sand, limestone, etc.) to enhance the characteristics of structural elements or to modify the functional characteristics or the aspect of the finished products. Clays are hydrated aluminosilicates whose lamellar structure can fix a certain quantity of
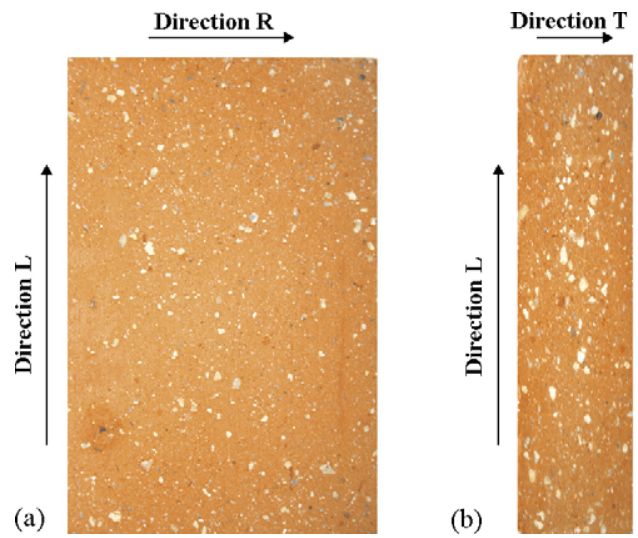

(c)

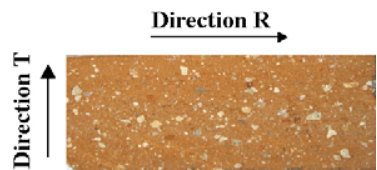

Fig. 3. Illustration of the grain distribution and the grain orientation in the different directions. 


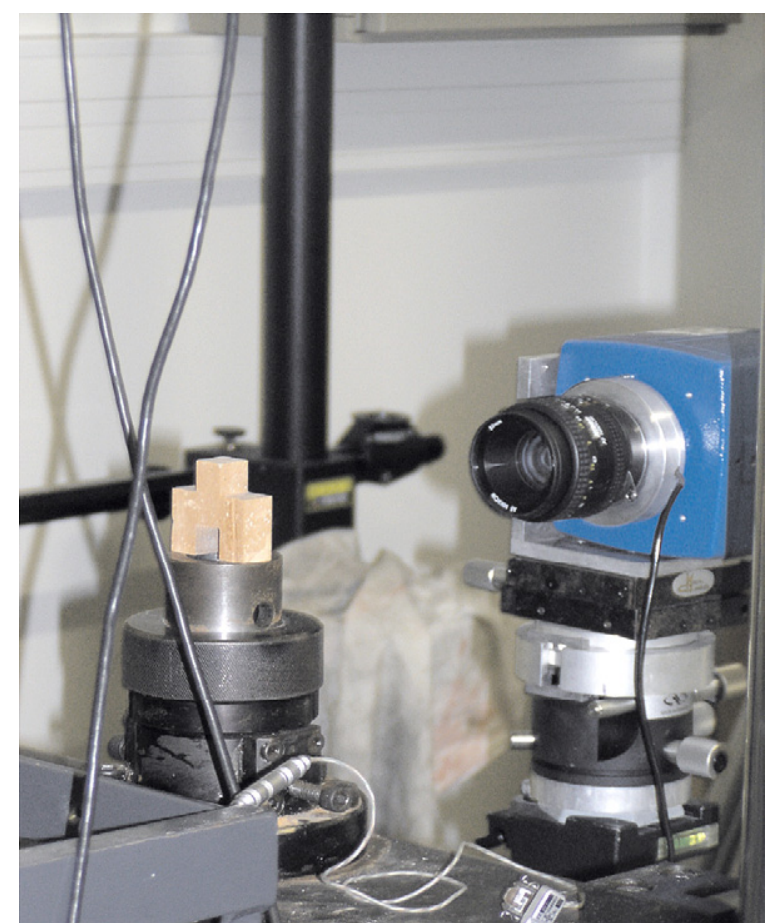

Fig. 6. Experimental device - testing machine coupled to a digital video camera.

water between folia. Four stages are required to obtain the end product:

- preparation: to obtain an argillaceous mixture after proportioning and crushing the components;

- forming: generally by extrusion;

- drying: to eliminate almost all of the water used during the forming stage;

- firing: the duration depends on the size of the terra cotta components, generally within the $800-1200^{\circ} \mathrm{C}$ temperature range.

\subsection{Material porosity}

The Fig. 2 gives an image with an enlargement 10 times higher than Fig. 1. A qualitative analysis reveals a fine and homogeneous porosity of the material, however it is difficult to quantify this porosity.

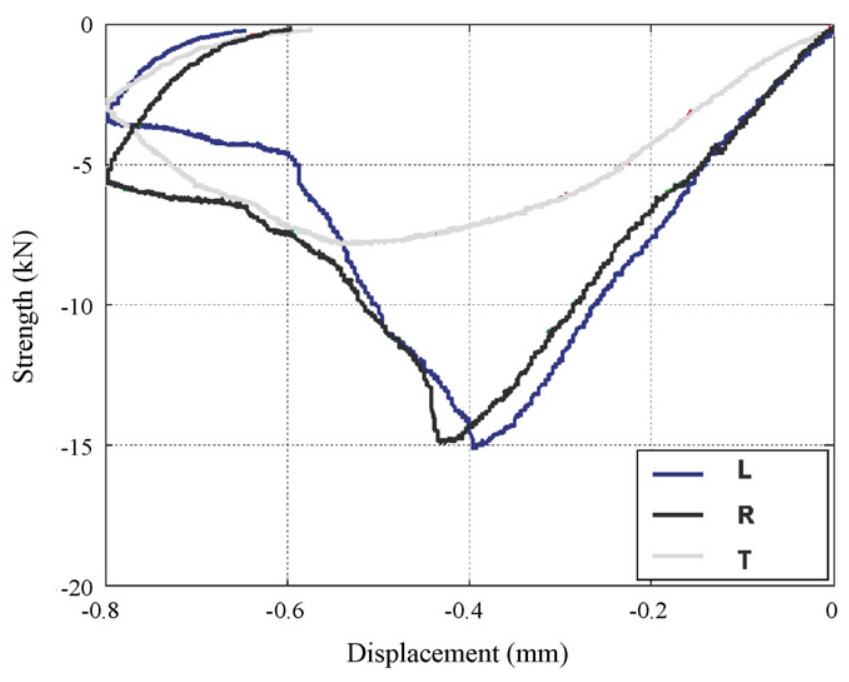

Fig. 8. Compression tests according to the directions $R, L$ and $T$ - sample responses.

Table 1

Chemical composition of terra cotta ceramics

\begin{tabular}{lc}
\hline Elements & (at.\%) \\
\hline $\mathrm{SiO}_{2}$ & 57.9 \\
$\mathrm{Al}_{2} \mathrm{O}_{3}$ & 15.4 \\
$\mathrm{CaO}$ & 14.4 \\
$\mathrm{Fe}_{2} \mathrm{O}_{3}$ & 4.9 \\
$\mathrm{TiO}_{2}$ & 0.4 \\
$\mathrm{MgO}$ & 1.4 \\
$\mathrm{~K}_{2} \mathrm{O}$ & 4.3 \\
$\mathrm{Na}_{2} \mathrm{O}$ & 1.3 \\
\hline
\end{tabular}

Table 2

Data summary of the analysis by mercury intrusion porosimetry

\begin{tabular}{lc}
\hline Median pore diameter $(\mu \mathrm{m})$ & 3.69 \\
Bulk density $\left(\mathrm{kg} \mathrm{m}^{-3}\right)$ & 2011 \\
Apparent $(\mathrm{skeletal})$ density $\left(\mathrm{kg} \mathrm{m}^{-3}\right)$ & 2713 \\
Porosity $(\%)$ & 25.9 \\
\hline
\end{tabular}

Table 3

Average value and standard deviation of experimental results obtained for $E_{L}$, $E_{R}$ and $E_{T}$

\begin{tabular}{lcll}
\hline & Number of tests & Average value $(\mathrm{GPa})$ & Standard deviation $(\mathrm{GPa})$ \\
\hline$E_{L}$ & 10 & 20.2 & 2.8 \\
$E_{R}$ & 6 & 19.8 & 3.1 \\
$E_{T}$ & 8 & 5 & 0.3 \\
\hline
\end{tabular}
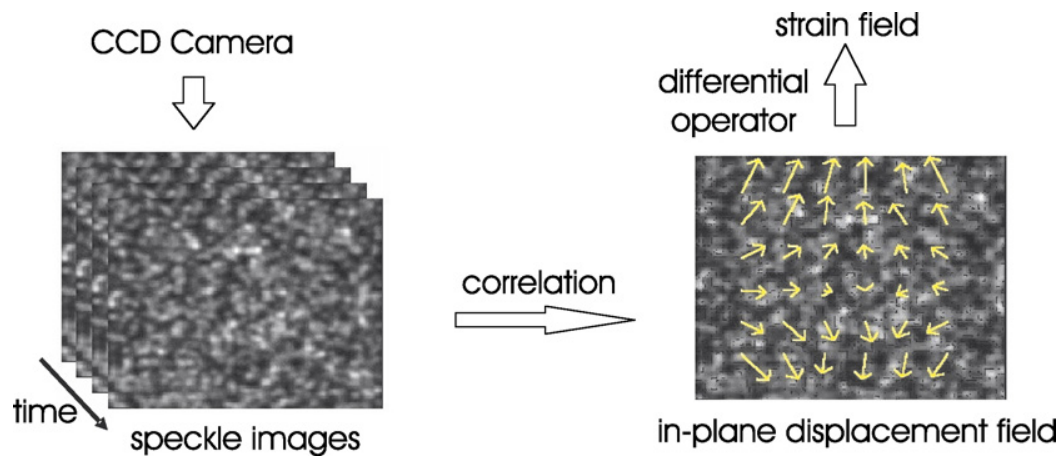

Fig. 7. Basic sketch of the DIC techniques. 

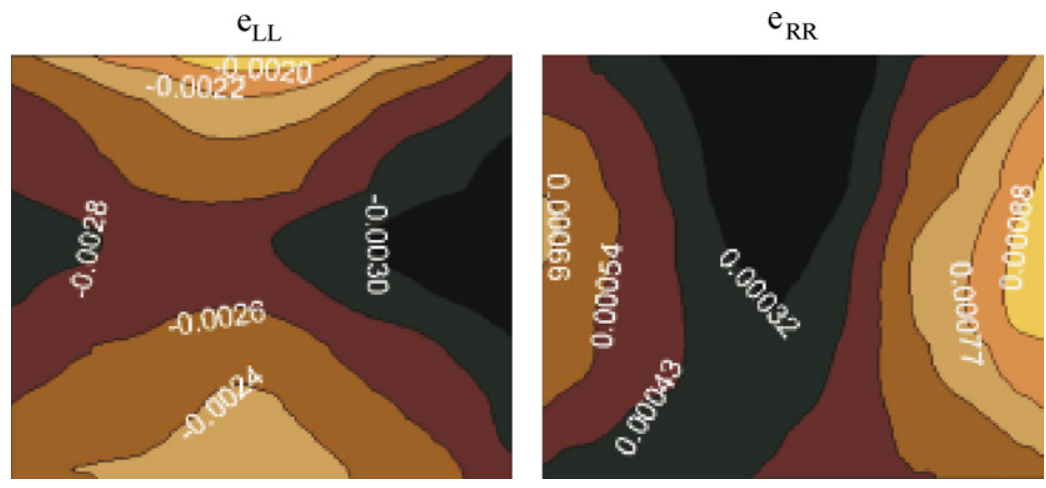

Fig. 9. $\varepsilon_{L L}$ and $\varepsilon_{T T}$ strains-compression in the direction $L$.

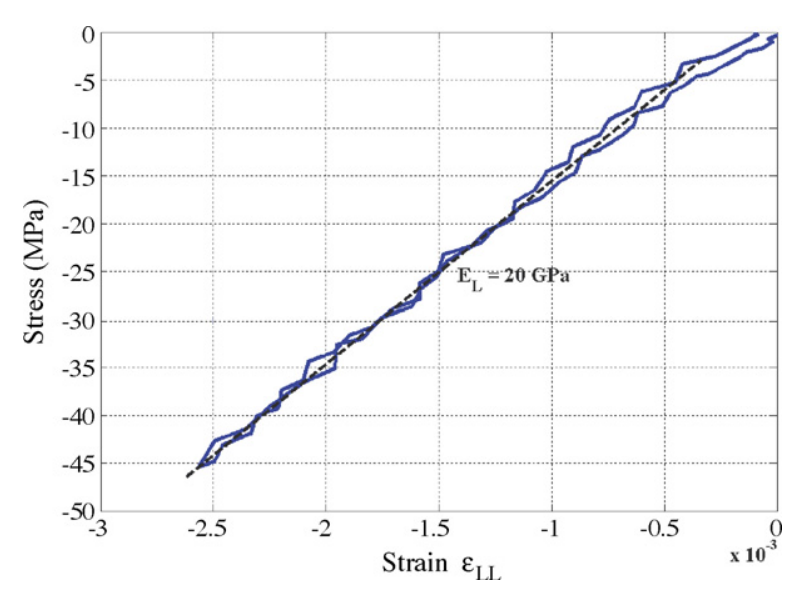

Fig. 10. Stress-strain diagram for a compression test in the $L$ direction associated with a load-unload cycle.

Table 4

Compression load supported by the Y-shaped sample: measurement and computation

\begin{tabular}{lll}
\hline & $F_{\text {exp }}$ & $F_{\text {comp }}$ \\
\hline$t=6 \mathrm{~s}$ & 0.32 & 0.37 \\
$t=12 \mathrm{~s}$ & 2.17 & 2.36 \\
\hline
\end{tabular}

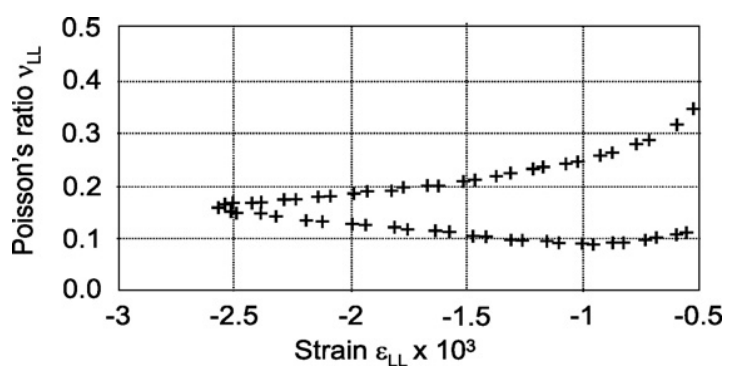

Fig. 11. Evolution of the Poisson's ratio $v_{L T}$ associated with the loading in Fig. 10 .

A mercury intrusion porosimetry was accomplished on the same sample. The results give more useful data as shown on the Table 2.

\subsection{Anisotropic behavior}

The different stages of forming process induce an anisotropic and heterogeneous thermomechanical behavior of the terra cotta structural elements. The extrusion process involves a privileged direction and leads to transverse isotropy of the material. The grain distribution and the grain orientation can be directly observed by using a standard camera as shown in the Fig. 3. The three photos enabled us to see the random distribution of the quartz grains in the isotropic plane (Fig. 3a), while a privileged direction can be seen in the others (Fig. $3 b$ and c). This also induces gradients of elastic properties throughout the structure,
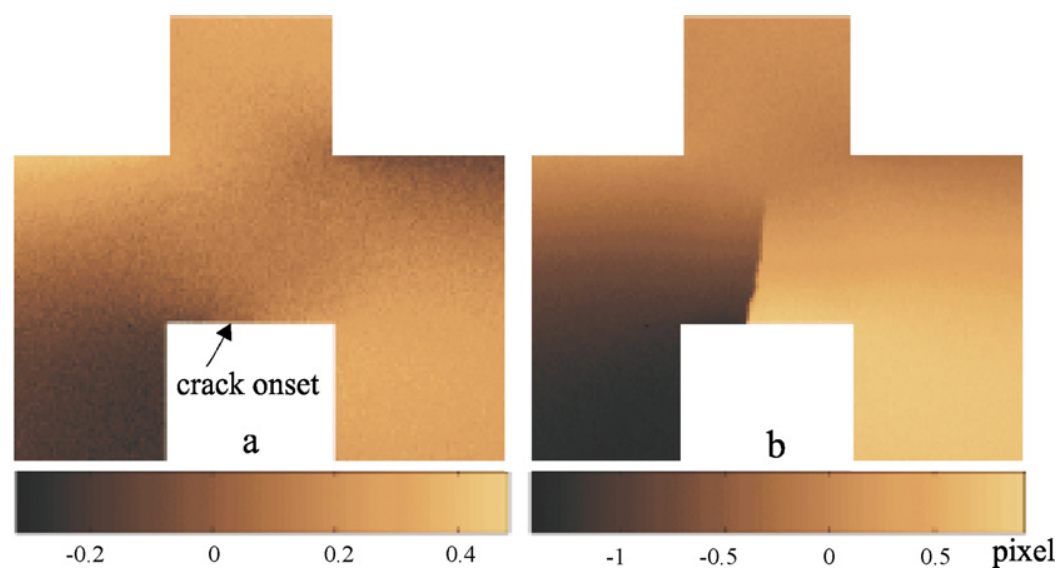

Fig. 12. Displacement pattern of $u_{L}$ (scale factor: $17 \mu \mathrm{m} /$ pixel): (a) crack onset, (b) crack growth 

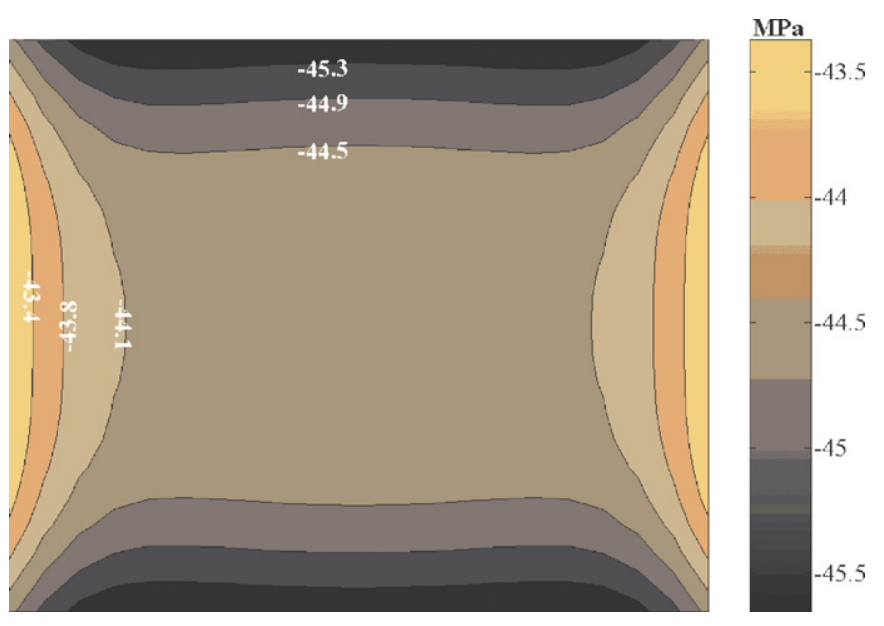

Fig. 13. Normal stress field on the middle cross section.

especially between the boundary and the core of the extruded parts. Besides, these gradients are often amplified and disturbed by the drying and firing processes because of mass and heat transfers and by the material heterogeneity due to the irregular distribution of pores and the varied granulometry of the mixture despite the preparation stage. We were led to use sets of specimens randomly extracted from an extruded structure to estimate discrepancies in the elastic parameters.

To define transverse isotropy axes, we introduced $L$ as the direction of extrusion, $T$ the direction across the layers of terra cotta and $R$ the direction in the plane of the layers, i.e. orthogonal with $L$ and $T$ (Fig. 4). The five elastic constants to be determined are then: Young's moduli $E_{L}=E_{R}$ and $E_{T}$; Poisson's ratios $v_{L R}$ and $v_{L T}=v_{R T}$; Shear moduli $G_{L T}=G_{R T}$. Due to the isotropy of the plane of the layers, the shear modulus $G_{L R}$ can be written as $G_{L R}=E_{L} /\left(2\left(1+v_{L R}\right)\right)$.

Using engineering notations, the strain-stress relationship may be written as:

$$
\left(\begin{array}{c}
\varepsilon_{L L} \\
\varepsilon_{R R} \\
\varepsilon_{T T} \\
\varepsilon_{L R} \\
\varepsilon_{R T} \\
\varepsilon_{L T}
\end{array}\right)=\left[\begin{array}{cccccc}
\frac{1}{E_{L}} & -\frac{\nu_{L R}}{E_{L}} & -\frac{v_{L T}}{E_{L}} & 0 & 0 & 0 \\
-\frac{v_{L R}}{E_{L}} & \frac{1}{E_{L}} & -\frac{v_{L T}}{E_{L}} & 0 & 0 & 0 \\
-\frac{v_{L T}}{E_{L}} & -\frac{\nu_{L T}}{E_{L}} & \frac{1}{E_{T}} & 0 & 0 & 0 \\
0 & 0 & 0 & \frac{1+v_{L R}}{E_{L}} & 0 & 0 \\
0 & 0 & 0 & 0 & \frac{1}{2 G_{L T}} & 0 \\
0 & 0 & 0 & 0 & 0 & \frac{1}{2 G_{L T}}
\end{array}\right]\left(\begin{array}{c}
\sigma_{L L} \\
\sigma_{R R} \\
\sigma_{T T} \\
\sigma_{L R} \\
\sigma_{R T} \\
\sigma_{L T}
\end{array}\right)
$$

where $\varepsilon_{I J}$ and $\sigma_{I J}$ are the matrix components of the strain and stress tensors with respect to the $L R T$ frame.

\section{Experimental protocol}

\subsection{Realization of samples}

Building engineering standards do not give any dimensional specifications for terra cotta specimens. Moreover, in the scientific literature, we found no examples of terra cotta specimens adapted for classical mechanical tests such as tension-compression tests, shearing and bending tests. We thus based our study on guidelines for the characterization of cements or mortars with granular sizes similar to that of terra cotta. Although compression tests are generally performed on specimens with a ratio of 2, we decided to use of cubic samples of
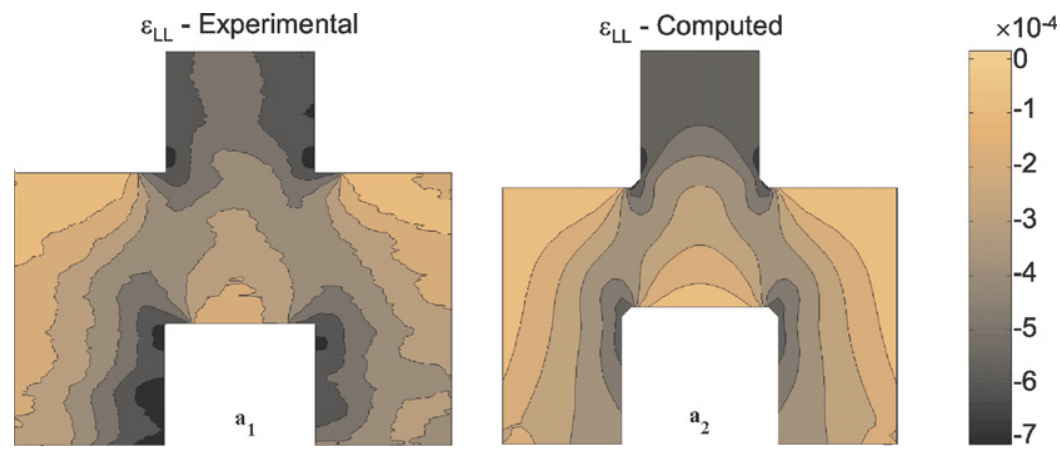

Fig. 14. Fields of strain $\varepsilon_{L L}$ : (a1) digital image correlation; (a2) 3D FE calculation.
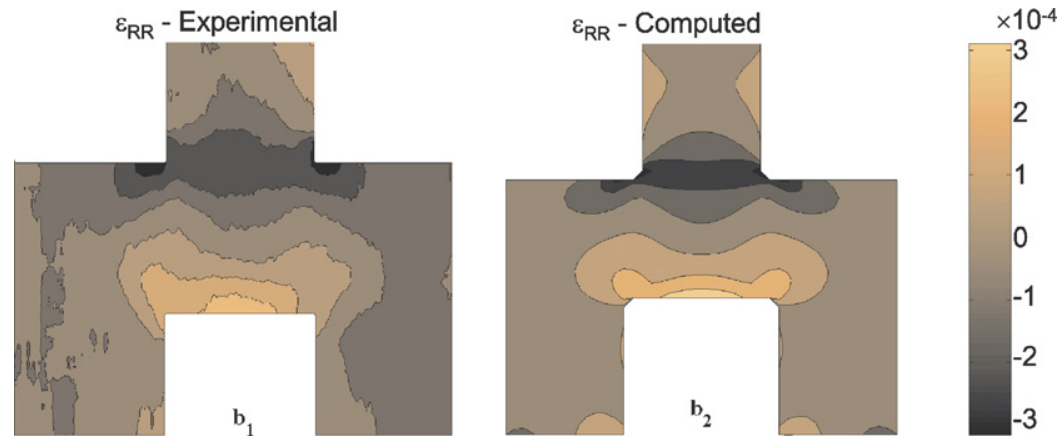

Fig. 15. Fields of strain $\varepsilon_{R R}$ : (b1) digital image correlation; (b2) 3D FE calculation. 


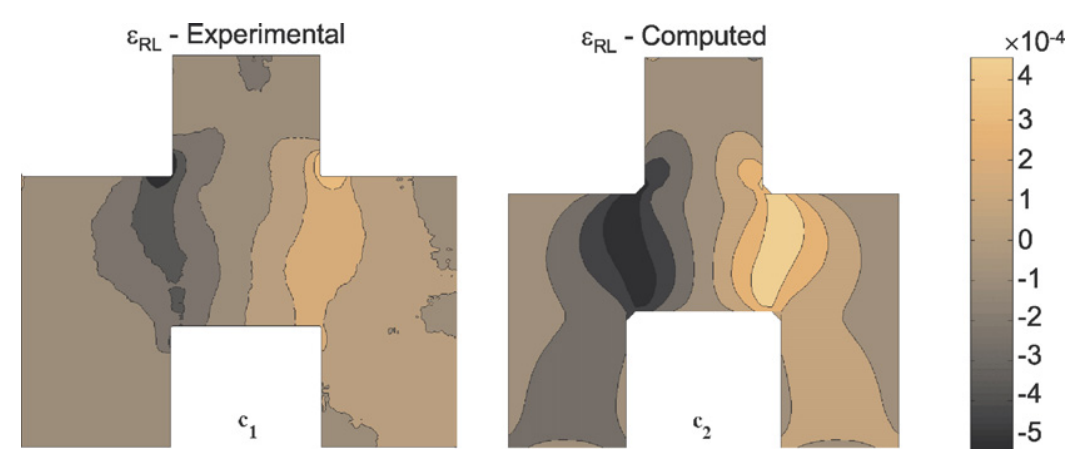

Fig. 16. Fields of strain $\varepsilon_{R L}$ : (c1) digital image correlation; (c2) 3D FE calculation.

reduced sizes (sides: $15 \mathrm{~mm}$ ) in order to ensure a quite good homogeneity of these elementary structures at the risk of getting a
Between two images $I_{1}$ and $I_{2}$ (Fig. 7), separated by a small strain increment, $\varphi$ is written as:

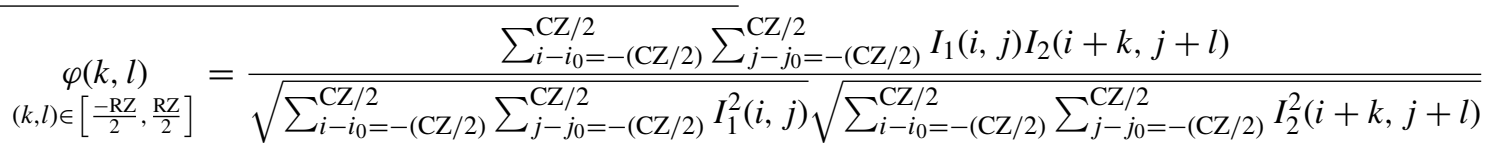

triaxiality effects due to the compression plates. The specimens were machined using a water jet cutting process to avoid geometrical defects.

The compression tests, performed on cubic samples with transverse isotropy axes, gave access to the three elastic moduli and the three Poisson's ratios.

The shear modulus $G_{L R}$ was determined in the shearing zone of the Y-shaped specimen whose cross-section is given in Fig. 5. For this type of geometry, it is easy to obtain a layer plane parallel to the cross-section. Conversely, the extrusion process does not allow shearing specimen leading to measurement of $G_{L T}$ and $G_{R T}$. At this level, ultrasonic goniometry measurements were used to determine both missing shear moduli and to check the modulus estimates and the Poisson's ratios obtained mechanically. ${ }^{2-4}$

\subsection{Experimental set-up}

The experimental set-up involved a $100 \mathrm{kN}$ tensioncompression servo-mechanical testing machine. Digital images were recorded during the test by a CCD camera set in front of the sample (Fig. 6). The lens axis of the camera was fixed according to the frame of the testing machine and remained perpendicular to the surface of the sample. The CCD sensor had eight square megapixels distributed in a 3500 line $\times 2300$ column grid. The camera provided maximum space resolution from 0.01 to $0.02 \mathrm{~mm} / \mathrm{pixel}$ with the "macro" lens we used during the tests. For images of maximum size, the camera can capture up to five images a second digitized in eight bits.

\subsection{Displacement and strain measurements}

The in-plane displacement components were computed by a direct DIC algorithm on each point $M_{0}\left(i_{0}, j_{0}\right)$ of a virtual grid defined in the reference configuration. The position of the discrete maximum of the discrete inter-correlation function $\varphi$ gives the displacement of point $M_{0}$ with a one pixel resolution.
In Eq. (2), $C Z$ stands for the correlation zone (i.e. the $M_{0}$ neighborhood defining the optical signature of "point" $M_{0}\left(i_{0}, j_{0}\right)$ ), and RZ is the research zone (i.e. the $M_{0}$ neighborhood where the optical signature is tracked). These zones correspond to the domain of variation of $(i, j)$ and $(k, l)$, respectively. To obtain sub-pixel measurements, we used a polynomial interpolation of $\varphi$ in the vicinity of its discrete maximum. ${ }^{5}$

Heterogeneous strain field analysis considers small "gauge lengths" that induce a poor signal-to-noise ratio. Consequently, a local least-squares fitting of the displacement data is performed before any differentiation: the displacement field is locally approximated in the neighborhood of each point $M_{0}$ by a given function. Both the shape of the approximation function and the size of the approximation zone (AZ) may affect the accuracy of the strain measurement. Here we decided to use bilinear functions as they are associated with a locally constant deformation. For more information, the reader may refer to. ${ }^{6}$ The image processing performance was tested either in analytic and experimental cases corresponding to rigid body motion, to homogeneous or heterogeneous strain. ${ }^{6}$

\section{Experimental results and discussion}

\subsection{Global response of the samples}

Rupture tests in compression performed at constant velocity $\left(0.1 \mathrm{~mm} \mathrm{~s}^{-1}\right)$ were initially conducted on cubic specimens in the three directions $L, R$ and $T$. Fig. 8 illustrates the results obtained. We obtained similar sample responses in compression tests in directions $L$ and $R$. This feature is consistent with the transverse isotropy hypothesis. At the beginning of the loading process, the cubic structure has an elastic response until the maximum load was reached. Then the softening part of the curve corresponds to the propagation of micro-cracks throughout the sample. Compression in the direction $T$ was performed perpendicular to the plane of the layers. This configuration gave the structure greater compliance and seemed to be less favorable for the propagation and coalescence of microscopic cracks. 


\subsection{Material response}

Based on previous results, the tests were carried out while limiting maximum compressive loading in order to ensure an elastic response of the structure. These tests were performed at constant velocity $\left(0.1 \mathrm{~mm} \mathrm{~s}^{-1}\right.$ during loading and $0.5 \mathrm{kN} \mathrm{s}^{-1}$ during unloading). The strain field measurements were first used to check the boundary conditions during loading. Some examples of strain patterns obtained by DIC are shown in Fig. 9 and correspond to components $\varepsilon_{L L}$ and $\varepsilon_{T T}$ of the strain tensor. Both fields were extracted from a compression test in direction $L$ at maximum loading $(\approx 11 \mathrm{kN})$.

We observed slightly heterogeneous deformation fields, which were not in full agreement with the kinematics of a simple compression test. The strain level curve distributions highlighted that this non-uniformity was partly due to the boundary conditions at the specimen surfaces in contact with the compression plates. The irregular patterns noted for level curves could also have been associated with the material heterogeneities and, of course, with the noise on strain measurements. The fields could be interrelated with the finite element calculation using displacement boundary conditions corresponding to those observed experimentally. The stress-strain curve corresponding to measurements obtained in the central area of the specimen is plotted in Fig. 10. The compression strain $\varepsilon_{L L}$ is directly derived from speckle image processing, while the compression stress $\sigma_{L L}$ is determined by assuming a uniform stress distribution over the cross-section. Then a simple regression is used to estimate the elasticity modulus ( $E_{L}$ in Fig. 10). All results for the estimation of Young's modulus are given in Table 3. Note that the standard deviations obtained on moduli using a random set of about 10 samples were about $4 \mathrm{GPa}$ for mean values of about $20 \mathrm{GPa}$. This discrepancy is very substantial and illustrates the heterogeneity between specimens.

Fig. 11 presents several estimates of Poisson's ratio $v_{L T}=$ $-\varepsilon_{T T} / \varepsilon_{L L}$ for different $\varepsilon_{L L}$. As previously underlined, this computation assumes a uniform compression state in the central part of the sample. The increasing discrepancy of measurements observed when strain components were around zero was associated with degradation of the signal to noise ratio. Therefore only estimates of the Poisson's ratios for $\left|\varepsilon_{L L}\right|>5 \times 10^{-4}$ were considered.

Tests were performed on Y-shaped specimens to determine the shear modulus $G_{L R}$ (see Fig. 5). These tests were performed at constant velocity $\left(0.01 \mathrm{~mm} \mathrm{~s}^{-1}\right.$ during loading and $0.5 \mathrm{kN} \mathrm{s}^{-1}$ during unloading). We noted two phases in the structural response: the first corresponded to a quasi-elastic behavior while the second started with the inception of the first macroscopic crack. Fig. 12 illustrates the potentials of correlation methods regarding micro-crack detection. The displacement field features (here component $u_{L}$ ) enabled us to visualize crack onset and propagation at the sample surface as soon as its opening was not parallel to the direction of the chosen displacement component. The amplitude of the displacement discontinuity may be related to the crack opening.

Fig. 16c1 presents the $\varepsilon_{R L}$ distribution and shows the significant sliding "shearing" zones. In these zones, we estimated a mean shear stress and a mean sliding strain to obtain the $G_{L R}$. As mentioned above, the other shear moduli were classically obtained using ultrasonic techniques.

The average elasticity constant values we obtained are: $E_{L}=$ $E_{R}=20 \mathrm{GPa} ; E_{T}=5 \mathrm{GPa} ; v_{L R}=0.17, v_{L T}=v_{R T}=0.15$; $G_{L R}=8.8 \mathrm{GPa}, G_{L T}=G_{R T}=3 \mathrm{GPa}$.

\section{Validation procedure}

\subsection{Experimental and computed results on cubic specimens}

The elastic modulus estimates were checked by comparing the local stress values obtained in the central area by 3D Finite Elements computations with the compression stress deduced from the loading data. The numerical model takes transverse isotropy elasticity into account and supposes that the material is homogeneous. The elasticity tensor takes the predetermined mean values into account. It also supposes that the axis of compression is one of the transverse isotropy axes. Loading was modeled by displacement fields imposed at the surfaces in contact with the compression plates. These boundary conditions were directly extracted from displacement data obtained by DIC. Fig. 13 presents the results obtained for a simulated compressive test in the $L$ direction. Considering a cross-section placed in the medium part of the specimen, computations enabled us to estimate, at maximum elastic loading, a mean value for the compression stress pattern $\left(\bar{\sigma}_{L L}\right)_{\text {comp }}$ of about $44.5 \mathrm{MPa}$. The standard deviation associated with this distribution was about $0.6 \mathrm{MPa}$. Hence, the stress state, imposed by the experimental boundary conditions, was uniform in a first good approximation. Compression stress $\left(\sigma_{L L}\right)_{\exp }$ can also be estimated assuming, as usual, a uniform stress state over the cross-section and using the load measurements. We found that $\left(\sigma_{L L}\right)_{\exp }$ was about $43.5 \mathrm{MPa}$. The difference between $\left(\sigma_{L L}\right)_{\exp }$ and $\left(\bar{\sigma}_{L L}\right)_{\text {comp }}$ remained small, thus partly confirming the previous approximations.

\subsection{Experimental and computed results on $Y$-shaped specimens}

We checked the overall consistency of the characterization procedure by comparing strain fields obtained in Y-shaped samples with those resulting from FE computations. Loading was modeled by displacements obtained by DIC imposed at surfaces in contact with the compression plates. The computed and experimental strain patterns are compared in Figs. 14-16. We noted a satisfactory global correlation between both distributions, regardless of the strain tensor component. Moreover, we noted a close correlation between the measurement and the calculation when comparing the overall loading applied to the structure (Table 4).

\subsection{Conclusion}

The results presented in this paper highlight the benefits of digital correlation techniques for characterizing and identifying the elastic behavior of anisotropic terra cotta ceramics. Full-field measurements were initially useful for checking the quality of the tests by analyzing the characteristics of the displacement 
fields near surfaces where loading boundary conditions were imposed. The kinematic data were also useful for the evaluation of elasticity constants of a transverse isotropic behavior model. A comparison between experimental and numerical results obtained on a Y-shaped terra cotta brick element showed that the set of identified elastic constants gave satisfactory results. To estimate the different elastic parameters and to perform 3D FE computations, we assumed that the material was and remained homogeneous during mechanical transformation. Other very promising approaches will be available in the near future ${ }^{7-9}$ to consider the local elastic properties of the material and to account for the structural heterogeneities leading to property gradients in civil engineering structures. The capabilities of these inverse approaches are presently being tested on academic (numerical) examples. ${ }^{10}$ In the near future, they will be applied to noisy and discrete data fields obtained by digital image correlation.

\section{Acknowledgments}

The authors would like to thank Saverdun Terre Cuite (STC), a French terra cotta building component manufacturer, for partly supporting this research work.

\section{References}

1. Wattrisse, B., Chrysochoos, A., Muracciole, J.-M. and Némoz-Gaillard, M., Kinematic manifestations of localisation phenomena in steels by digital image correlation. Eur. J. Mech. A: Solids, 2001;20:189211.

2. Preziosa, C., Mudry, M., Launay, J. and Gilletta, F. Détermination des constantes élastiques du bois par une méthode acoustique goniométrique. C. $R$. Acad. Sci. Paris, 1981;293(Série II):91-94.

3. Audoin, B., Baste, S. and Castagnede, B., Evaluation of the confidence interval associated with elastic constants identified from ultrasonic velocity measurements. C. R. Acad. Sci. Paris, 1991;312(Série II):679686.

4. Baudouin, S. and Hosten, B., Comparison between prediction and measurement of viscoelastic moduli composite materials versus temperature using ultrasonic immersion technique with oil. J. Acoust. Soc. Am., 1997;102(6):3450-3457.

5. Oulamara, A., Tribillon, G. and Duvernoy, J. Subpixel speckle displacement measurement using a digital processing technique. J. Mod. Opt., 1988;37:1201-1211.

6. Wattrisse, B., Chrysochoos, A., Muracciole, J.-M. and Némoz-Gaillard, M., Analysis of strain localization during tensile tests by digital image correlation. Exp. Mech., 2001;41(1):29-39.

7. Geymonat, G., Hild, F. and Pagano, S., Identification of elastic parameters by displacement field measurement. C. R. Mécanique, 2002;330:403408.

8. Claire, D., Roux, S. and Hild, F., Identification de conductivités thermiques et de propriétés élastiques locales par analyse de champs. Mécanique et Industries, 2003;4(6):655-665.

9. Bonnet, M. and Constantinescu, A., Inverse problems in elasticity. Inv. Prob., 2005;21:1-50.

10. Latourte, F., Chrysochoos, A., Geymonat, G., Pagano, S. and Wattrisse, B., Identification of elasto-plastic constitutive equations parameters using digital image correlation, Optical method and inverse identification, SEM 2005 Portland, CD Rom 1-608-873-4500. The Printing House Inc. Ed., Optical method and inverse identification, inverse problem I, pp. 349-356, 2005. 